\title{
Various Faculty Teaching Styles To Support Student Learning
}

\section{K. Gireesh}

Deputy Dean \& Vice-Principal, Department of Medicine, SRM Institute of Science and Technology, Chennai.

Corresponding Author: K. Gireesh

E-mail: gireesh_md@hotmail.com

\begin{abstract}
This paper will focus on the various teaching styles for effective implementation of any subject in the classroom. Indeed, teaching styles denote various strategies that teacher uses to deliver his/her subject matter to the students within the realm of the instructional objectives.

There are several teaching methods, but it is left for the teacher to use the appropriate style. The teaching style should match the learning style of the students. The teacher's task is to ensure that learning is effective by using the appropriate method. This paper examines the concept of teaching and learning styles and also discusses various other teaching methods that can be used in a flipped classroom.
\end{abstract}

Key words: teaching methods, learning methods, teacher.

Teaching is an activity being carried out in a professional manner to bring a positive change on the learner. The teacher apart from updating knowledge should keep abreast with the basic principles of teaching that will help the teacher to be efficient in the discharging his/her duties. Teachers do impart training by encompassing the three domains cognitive, affective and psychomotor domain of the learner. Apart from this teacher should also know the various learners' styles of listening. And then modify his/her teaching accordingly. It is very well hoped that this paper throws a light on the above aspects of teaching for the teacher [1-5]. Well in order to carry out an effective teaching a good teacher should identify the learning style of students.

Learning involves acquiring knowledge or skills, attitudes and thereby modifying the behavioural pattern of an individual.

The learning style of students are as follows [6]:

a) Avoidant style - They are not enthusiastic teaching the subject and disinterested in attending class. They do not participate in activities.

b) Collaborative style - These students feel that they can learn by sharing ideas and talents they cooperate with teachers. They like working as a team.

c) Competitive style - These students believe that they must compete and out do others. They do learn material with focus on competition. They like to be the center of attention and to receive recognition for their achievements.

d) Dependent style - They learn only what is required. They do expect to be taught by a teacher. They look upon teacher as an authority figure for specific guidelines on what to do. They prefer didactic lectures. 
e) Independent style - They participate in independent projects and are quite confident in their learning abilities. They prefer to work alone rather than with other students. They tend to determine their goals and learning process.

f) Participant style - They enjoy going to class and actively participate in all course activities. They do prefer lectures with discussion.

Students do have a combination of the styles too. As a teacher one has certain style of teaching which include [6]:

a) Authority or lecture style - This model is teacher centered and frequently consists of lengthy lecture sessions. Students should take notes. There may not be much interaction.

b) Demonstrator or coach style - Here the teacher demonstrates tarter what the student should know. And their lessons include multimedia presentations, activities and clinical demonstrations of physical signs.

c) Facilitator or activity style - Facilitators helps students to perform self-directed learning and develop analytical and critical thinking style. Also helps students to find answers and solutions through exploration. This challenges teacher to interact with students and also student to interact amongst each other.

d) Delegator or group style - As a delegator, teacher acts more as consultant and places the teacher in an observer role. It is best suited for lab activities such as Chemistry, Biology subjects' debate

e)

Although teaching styles have been categorized into various groups, today's ideal teaching style is more of a hybrid approach that blends the best of everything a teacher has to offer.

Hybrid or blended style - This style follows an integrated approach to teaching that blends the teachers' style and interest with students' needs. It enables teacher to tailor their style to student needs. Of course, it should focus the teaching objectives.

To make the class rooms interactive the use of laptops, video conferencing and podcasts play a vital role in today's teaching styles to accommodate the diverse needs of 21 st century classrooms.

$\begin{array}{ll}\text { Students style } & \text { Teachers style } \\ \text { Avoidance style } & \text { One to one coaching } \\ \text { Collaborative } & \text { Facilitator, Group work } \\ \text { Competitive } & \text { Delegator, Lecture, Interact } \\ \text { Dependent } & \text { Lecture method, Demonstrate method } \\ \text { Independent } & \text { Lecture, Delegator } \\ \text { Participant style } & \text { Lecture with interaction, Collaborative }\end{array}$

There is little doubt that the most dominant form of instruction is pedagogy, or what some people refer to as didactic, traditional, or teacher-directed approaches. A competing idea in terms of instructing adult learners, and one that gathered momentum within the past three decades, has been dubbed andragogy.

Pedagogy is derived from the Greek work "Paid" meaning child plus "agogos" meaning leading. Thus, pedagogy has been defined as the art and science of teaching children. In the pedagogical model, the teacher has full responsibility for making decisions about what will be learned, how it will be learned, when it will be learned, and if the material has been learned.

Andragogy (andr-meaning 'man') could be contrasted with pedagogy (paid-meaning 'child' and agogos meaning leading' [8].

In the minds of many around the adult education field, andragogy and the name of Malcolm Knowles [8] have become inextricably linked. For Knowles, andragogy is premised on at least four crucial assumptions about the characteristics of adult learners that are different from the assumptions about child learners on which traditional pedagogy is premised.

1. Self-concept: As a person matures his self-concept moves from one of being a dependent personality toward one of being a self-directed human being 
2. Experience: As a person matures he accumulates a growing reservoir of experience that becomes and increasing resource for learning.

3. Readiness to learn: As a person matures his readiness to learn becomes oriented increasingly to the developmental tasks of this social roles.

4. Orientation to learning: As a person matures his time perspective changes from one of postponed application of knowledge to immediacy of application, and accordingly his orientation toward learning shifts from one of subject-centeredness to one of problem centeredness.

5. Motivation to learn: As a person matures the motivation to learn is internal.

Lifelong learning is quite essential for medical experts so as to keep pace with the advancing knowledge and adapt to the dynamics of change which is a constant phenomenon in the medical subjects.

As the student enters from school to medical college they are coming from a pure pedagogical pattern to undergraduate that consists of a blend of Pedagogy and Andragogy. It will be like 60:40. As they go for Postgraduation ratio of Pedagogy and Andragogy will be 20:80. But there is a strong view that even in undergraduate medical education Andragogy should dominate so that the stimulus for lifelong learning is inculcated at that stage itself.

A constant update of knowledge through lifelong learning is quite essential in the medical field. This will help to render the best decision making and treatment for the patient, which is not only based on the knowledge acquired but also on the experience of doctors which is equally essential especially in the field of medicine. The latter human experience as one tool of education has been coined as humanagogy by Knudson [9].

Knudson [9] promotes humanagogy as a theory of learning that takes into account the differences between people of various ages as well as their similarities. It is a human theory of learning as opposed to a theory of child, adult or elderly learning. The accumulation of experience for example is a lifelong process that needs to be considered in educational planning. Inclusion of experience too likens this to a holistic approach of adult education [7].

What I strongly feel is that, for a lifelong learner in medical education, the best form will be a blend of Pedagogy, Andragogy and Humanagogy.

The Andragogy method can be implemented in a flipped class room teaching. Indeed, the flipped classroom is a teaching method that delivers lecture content to students at home through electronic means and uses class time for practical application activities which can motivate self-directed learning. It was promulgated by Jonathan Bergmann and Aaron Sams, high school chemistry teachers from Colorado, who began using recorded lecture in 2006 [3].

The flipped classroom has two components: moving the lecture outside the class, usually delivered through electronic means and moving the practical application assignments, formerly homework, into the classroom. The lecture format has evolved from sliders, audio, podcasts, or narrated presentation to video casts that may incorporate animations, screen captures and other multimedia content.

The strengths of flipped classroom are as follows -

More active learning opportunities, increase one to one interaction between student and teacher, inculcate the habit of self-directed learning, students are active and get involved rather than being inactive, more time to clarify material, more time to explore concepts deeply, more time for additional learning as various inputs from peers are there, more time for active learning, structured exercises help students to manage in small groups, more time for extended class room discussions, increase student responsibility for their own learning, work with peers to solve problems, fill eachothers knowledge gaps, gradually build their own knowledge coordinating with what they already know. 
Students may initially have confusion or discomfort but if instructor guides them properly and tell them what they are expended to do, then student understands and will enjoy traversing this rosy path of learning.

Indeed, in this model, student will be expected to know enough when they come to class to engage with each other.

During the flipped classroom as the students prepare and present they will be using the following various methods of learning:
1. Case study
2. Debates
3. Discussion
4. Panel discussion
5. Role playing
6. Simulation
7. Brain storming
8. Demonstration
9. Flip chart writing
10. Student centered cooperate learning
11. Web browsing

All the above will encompass cognitive affective and Psychomotor development methods.

\section{Conclusions}

Teaching is an attempt to bring about desirable changes in human behavior and learning abilities. Teaching methods should facilitate student learning and inculcate the habit of self-directed learning, so that it can be converted to lifelong learning. The flipped classroom model focuses on efficient use of class time and can accommodate different learners with varied styles. It allows students to take an active involvement in learning and use the array of teaching methods to present the contend efficiently. The teacher as facilitator can guide and use a combination of teaching methods for effective learning.

\section{REFERENCES}

1. Azarkhordad A, Mehdinezhad V. Explaining the students' learning styles based on GrashaReichmann's student learning styles. Journal of Administrative Management, Education and Training. 2016;12(6):72-9.

2. Khandaghi $M$, Rajaei $M$. Impact of students' style of learning on their preferred style of learning; $J$ Educat Psychol 2013;28.

3. Bergmann J, Sams A. Flip your classroom: Reach every student in every class every day. International Society for Technology in Education; 2012.

4. Duff A. The role of cognitive learning styles in accounting education: developing learning competencies. Journal of Accounting Education 2004;22(1):29-52.

5. Grasha AF. An integrated model of teaching and learning style: In Teaching with Style: A Practical Guide to Enhancing Learning by Understanding Teaching and Learning Styles. San Bernardino, Calif: Alliance Publishers. 1996.

6. Karimi MM. Relation Between Learning Styles and Student Performance in Architecture Design Studios.

7. Knowles MS, Holton III EF, Swanson RA. The adult learner. Routledge: UK; 2012.

8. Knudson RS. Humanagogy anyone?. Adult Educ 1979;29(4):261-4.

9. Long HB. Self-Directed Learning: Emerging Theory \& Practice. Oklahoma Research Center for Continuing Professional and Higher Education, McCarter Hall, University of Oklahoma, Norman; 1989. 